"New carbamate supports for the preparation of 3'-amino-modified oligonucleotides." Aviñó, A., Güimil-Garcia, R., Albericio, F., Mann, M., Wilm, M., Neubauer, G., Eritja, R. Biorg. \& Med. Chem., 4(10), 1649-1658 (1996).

doi: 10.1016/0968-0896(96)00156-3

\title{
New Carbamate Supports for the Preparation of 3'-Amino modified Oligonucleotides
}

\section{Anna Aviñó, a,b Ramon Güimil Garcia, b Fernando Albericio, ${ }^{c}$ Matthias Mann, ${ }^{b}$ Matthias Wilm, ${ }^{b}$ Gitte Neubauer $^{b}$ and Ramon Eritja ${ }^{a, b, *}$}

aDepartment of Molecular Biology, Centro de Investigación y DesarrolloCSIC, Jordi Girona 18-26, E-08034 Barcelona, Spain

bEuropean Molecular Biology Laboratory, Meyerhofstrasse 1, D-69117 Heidelberg, Germany

'Department of Organic Chemistry, Facultat de Química, Universitat de Barcelona, Marti i Franqués 1-1I, E-08028 Barcelona, Spain

Abbreviations: bz: benzoyl; CDI: 1,1'-carbonyl diimidazole; CPG: controlled pore glass; DBU: 1,8-diazabicyclo[5.4.0]undec-7-ene; DMAP: 4(dimethylamino)pyridine; DCC: dicyclohexylcarbodiiimide; DMF: N,Ndimethylformamide; DMT: 4,4'-dimethoxytrityl; ibu: isobutyryl; FMOC: 9fluorenylmethoxycarbonyl; HOBt: 1-hydroxybenzotriazole; LCAA: long-chain amino alkyl; NPC: p-nitrophenyl chloroformate; NPEOC: o- and pnitrophenylethoxycarbonyl.

Abstract-A novel approach for the preparation of oligonucleotides carrying amino groups at the 3 '-end is described. Several CPG supports having aminoalkyl groups and 3'-amino-2',3'-dideoxynucleosides linked through base-labile carbamate linkages such as 2-(2-nitrophenyl)ethoxycarbonyl and fluorenylmethoxycarbonyl were prepared using two different strategies. These supports are compatible to the standard solid phase phosphitetriester methodology and yield oligonucleotides containing amino groups at the 3'-end. Several properties of the 3'-amino oligonucleotides, such as nuclease resistance, hybridization, and preparation of oligonucleotide conjugates are discussed.

\section{Introduction}

Modified oligonucleotides having amino groups at the 3'- and the 5'ends are useful intermediates for the preparation of conjugates carrying a large variety of functionalities including fluorochromes, biotin, intercalators, enzymes, modifiers of cellular uptake, and reactive groups (1). Furthermore, it has been shown that 3'-amine oligonucleotides have an increased nuclease resistance that makes them good candidates for antisense studies $(2,3)$.

The introduction of amino groups at the 5 '-end of oligonucleotides is performed with phosphoramidites derived from 5'-amino nucleosides or 
from aminoalcohols $(1,4)$. The introduction of amino groups at the 3 '-end is more troublesome due to the need of special linker molecules to connect the desired amine to the solid support. These linker molecules should be stable to oligonucleotide synthesis conditions, but they should release the modified oligonucleotide during, after or before ammonia deprotection. The following linkers have been reported: (i) aminodiols such as 3-amino- 1,2propanediol (5), 2-aminobutyl-1,3-propanediol (6), N-(3-aminoprop-1-yl)$\mathrm{N}, \mathrm{N}$-bis(2-hydroxyethyl)amine (7), and 3,5-bis(hydroxymethyl)benzyl amine (8); (ii) phosphoramidate linkers $(9,10)$; (iii) phthalimido linkers (3, 11); (iv) glycolic and 4-hydroxybutyric esters (12); (v) 2, 2'-dithioethoxycarbonyl derivatives (13) (vi) 2'- and 3'-O-alkylaminoribonucleotides (14). Aminodiols are the most commonly used linkers for the preparation of 3'-amino oligonucleotides. Some of these linkers are commercially available and are used for the preparation of oligonucleotide conjugates.

Although base-labile carbamates such as fluorenylmethoxycarbonyl (FMOC) are commonly used for the protection of the amino groups in peptide synthesis, there is no description of similar groups for anchoring amino compounds such as 3'-amine oligonucleotides. The use of base-labile carbamates to anchor amine groups could eliminate the necessity of preparation of special trifunctional compounds and, in this way, facilitate the preparation of 3'-amine oligonucleotides. Also, the availability of polymeric base labile carbamates will open the possibility for the addition of different amine compounds at the 3'-end of oligonucleotides. As recently summarized by Manoharan (2) aliphatic amines at the 3'-end could have by themselves interesting properties, such as improved cellular uptake and enhanced stability to nuclease degradation. For these reasons, it will be interesting to have a fast and efficient method to prepare oligonucleotides having different amine compounds at the 3 '-end. In this report, we describe the use of solid supports having the base labile 2-(2 nitrophenyl)ethoxycarbonyl (NPEOC) (15) and FMOC (16) linkers for the preparation of 3'-amine oligonucleotides (Fig. 1). In order to test the new supports we have used aminoalcohols as model compounds of primary amino groups and 3'-amino- 2',3'-dideoxynucleosides as model compounds of secondary amino groups.
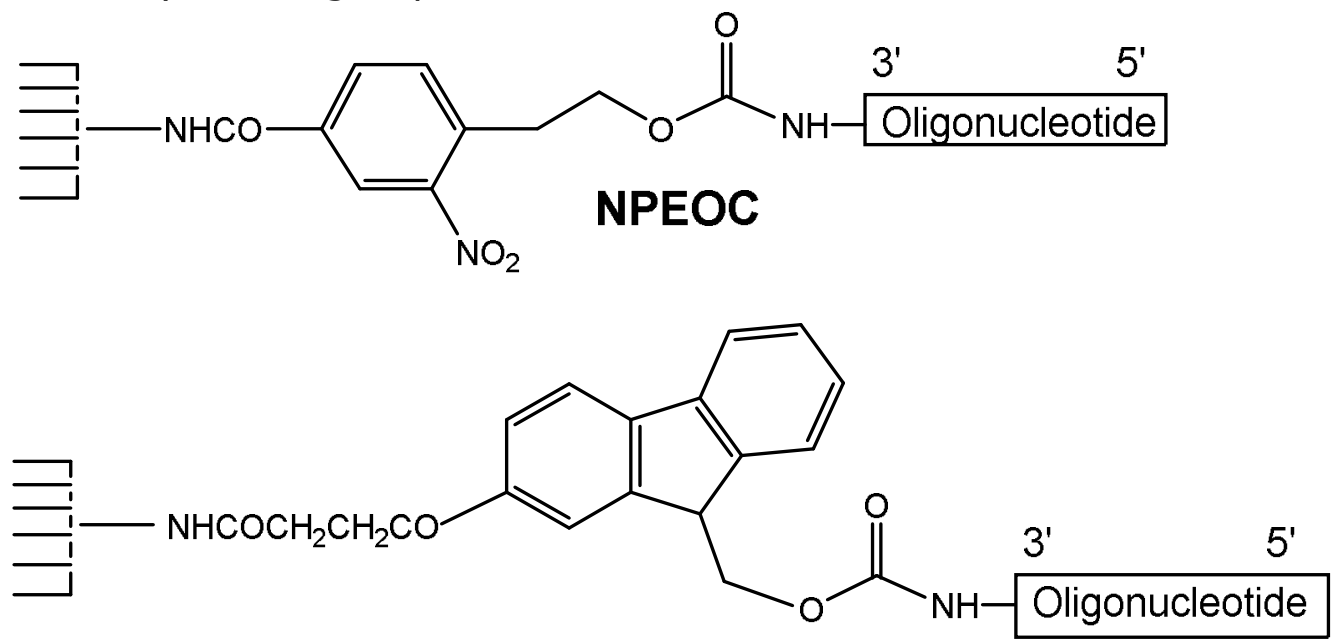

FMOC

Figure 1. Structure of NPEOC and FMOC carbamate linkages prepared in this work. 


\section{Results}

\section{Preparation of the amino derivatives}

Two types of amino derivatives have been selected to be introduced at the 3'-end of oligonucleotides: (1) amino alkyl derivatives such as 2aminoethanol, 3-aminopropanol, and 6-aminohexanol; and (2) 3'- amino 2',3'-dideoxynucleosides (uridine and cytidine). In order to be used for oligonucleotide synthesis the alcohol function of these compounds should be protected with the acid-labile dimethoxytrityl (DMT) group. The preparation of O-DMT-protected derivatives of 2-aminoethanol, 3-aminopropanol and 6aminohexanol is shown in Figure 2. The appropriate chloroalcohols were treated first with potassium phthalimide and the resulting phthalimido derivatives were reacted with dimethoxytrityl chloride in pyridine. Finally, the phthalimido group was removed with hydrazine hydrate giving the desired O-DMT-protected amino alcohols (1-3).

The key compound for the preparation of 5'-O-DMT- 3'-amino-2', 3'dideoxyuridine and cytosine was 5'-O-DMT-3'-azido-2', $3^{\prime}$-dideoxyuridine (6, Fig. 3). This compound was prepared from 5'-O-DMT-dU (4) via the 2,3'anhydro derivative (5) as previously described for the thymidine derivative (17-19). Conversion of the uridine derivative (6) to cytidine (8) was performed by activation of position 4 with mesitylensulfonyl chloride, formation of the 2-nitrophenyl derivative and displacement of the 2nitrophenyl group with ammonia. Afterwards, the amino group of the cytidine derivative (8) was protected with the benzoyl group using benzoyl chloride in pyridine. During the preparation of this manuscript, a shorter route has been described for the preparation of the cytidine derivative (19).

Finally, 5'-O-DMT-3'-azido-2',3'-dideoxynucleosides (6 and 9) were converted to the amino derivatives ( $\mathbf{7}$ and $\mathbf{1 0})$ using polymeric triphenylphosphine (20).

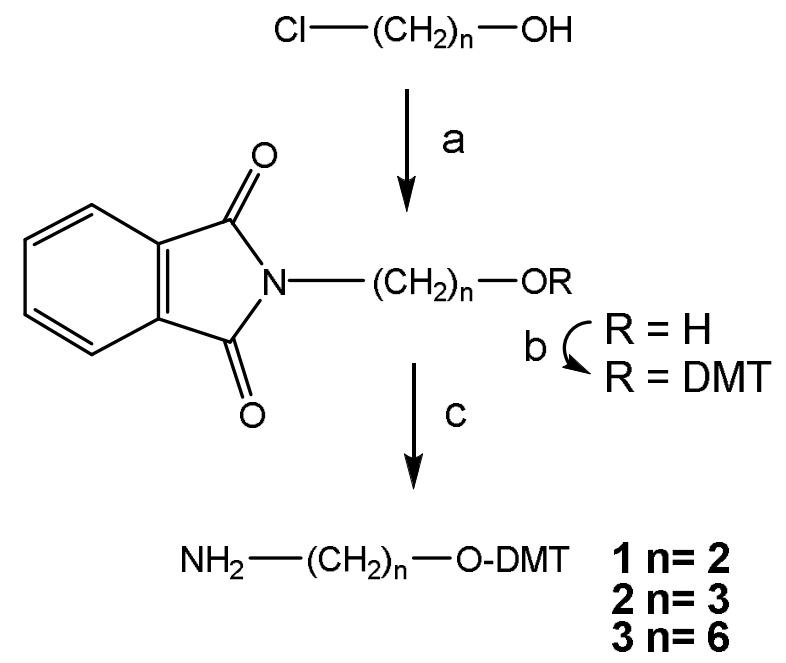

Figure 2. Preparation of $O-D M T$-protected derivatives of aminoalcohols 13. (a) potassium phthalimide, DMF, $60{ }^{\circ} \mathrm{C}$; (b) $\mathrm{DMT}-\mathrm{Cl}$, pyridine; (c) hydrazine hydrate. 


\section{Preparation of the supports}

Two different types of base-labile linkers were prepared: the ( $0^{-}$ nitrophenyl)ethoxycarbonyl (15) and the fluorenylmethoxycarbonyl (16) linkers. The synthesis of the corresponding carboxylic acid derivatives needed for incorporation on the polymeric support has been described previously $(15,16)$. We have tried two different routes for the preparation of the solid supports having the NPEOC linker (Fig. 4). In the first method, 1-O-DMT-6-aminohexanol was reacted with a chloroformate derivative of the linker molecule, obtaining a molecule that had the amino derivative connected to the linker, that was isolated, purified and characterized. In order to perform this reaction, the acid carboxylic function of the linker was protected as methyl ester. Selective saponification of the methyl ester (15) yielded the desired carboxylic acid that was reacted with amino-CPG. This route was named the 'solution method' because the reaction of the amino derivative with the linker was carried out in solution. In the second method, the linker molecule was reacted with the amino-CPG and the resulting support was activated either with 1,1'-carbonyldiimidazole (CDI) or with $p$ nitrophenyl chloroformate (NPC), followed by reaction with 1-0-DMT-6aminohexanol. This route was named the 'solid-phase method' because all the steps were performed on the solid support. The efficiency of the different methods was estimated by measuring the amount of DMT cation released upon acid treatment. The following loadings were obtained for the DMT-O- $\left(\mathrm{CH}_{2}\right)_{6}-\mathrm{NH}-\mathrm{NPEOC}-\mathrm{CPG}: 10 \mu \mathrm{mol} / \mathrm{g}$ using the 'solution method'; 20 $\mu \mathrm{mol} / \mathrm{g}$ using the 'solid-phase method' and activation with CDI and $13 \mu \mathrm{mol}$ $/ g$ if activation was performed with NPC. From these results and from the fact that the 'solid-phase method' was more easy to perform, we selected the 'solid-phase method' with CDI-activation for the preparation of the rest of the supports. Using this method, the following solid supports were prepared: DMT-O- $\left(\mathrm{CH}_{2}\right)_{6}-\mathrm{NH}-\mathrm{FMOC}-\mathrm{CPG}$, DMT-O- $\left(\mathrm{CH}_{2}\right)_{3}-\mathrm{NH}-\mathrm{NPEOC}-\mathrm{CPG}$, DMTO- $\left(\mathrm{CH}_{2}\right)_{2}-\mathrm{NH}-\mathrm{NPEOC}-\mathrm{CPG}$, DMT-O-3'-amino-ddCbz- NH-NPEOC-CPG, and DMT-O-3'-amino-ddU-NH-NPEOC- CPG. Loadings were in the range of $15-25 \mu \mathrm{mol} / \mathrm{g}$ except for the 3'-amino-2',3'-dideoxynucleosides that were 5$6 \mu \mathrm{mol} / \mathrm{g}$. This difference was assigned to a lower reactivity of the secondary amino group of 3'-amino-2',3'-dideoxynucleosides.

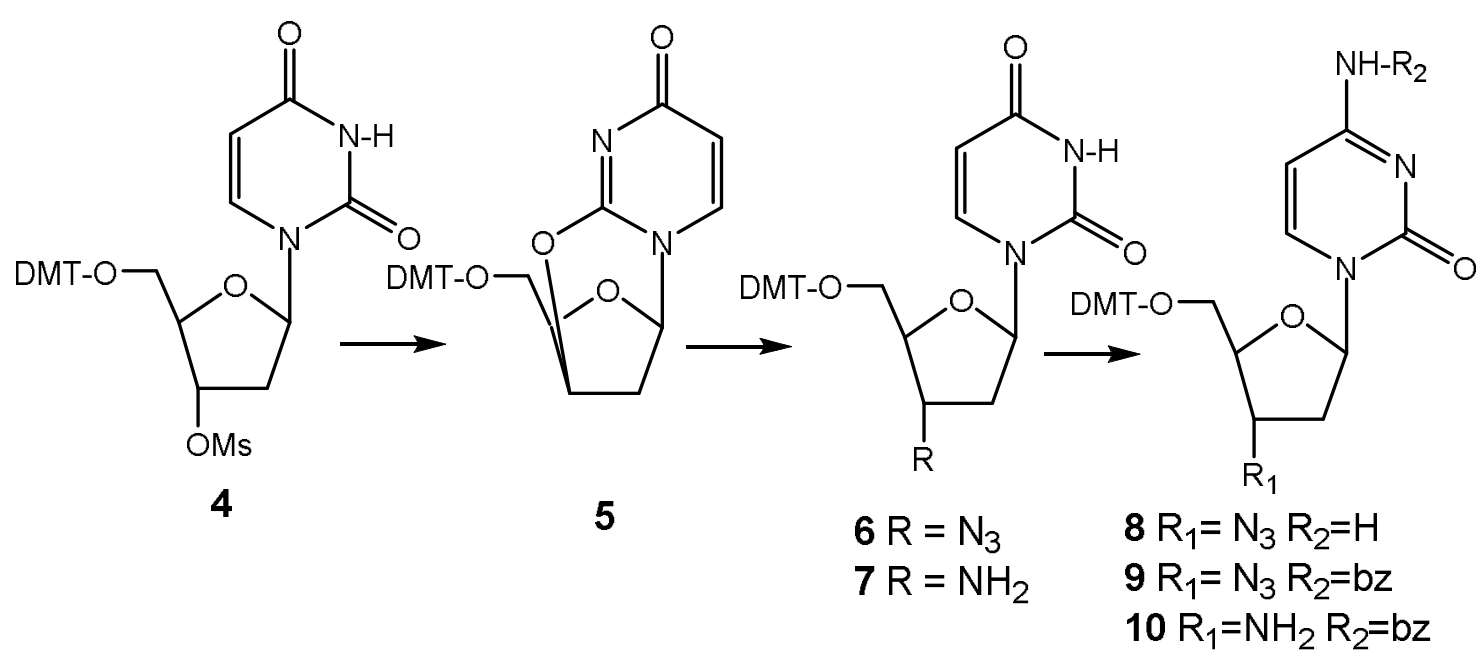

Figure 3. Preparation of 3'-amino-2',3'-dideoxyuridine and 3'-amino- 2' ,3'dideoxycytidine 


\section{Oligonucleotide syntheses}

First, hexanucleotide 5'CCGACC-phosphate- $\left(\mathrm{CH}_{2}\right)_{6}-\mathrm{NH}_{2}$ was prepared using DMT-O- $\left(\mathrm{CH}_{2}\right)_{6}-\mathrm{NH}-\mathrm{NPEOC}-\mathrm{CPG}$ made by the 'solution method' and the 'solid-phase method'. Syntheses were performed on an automatic DNA synthesizer using standard protocols and commercially available cyanoethyl phosphoramidites protected with benzoyl and isobutyryl groups. Coupling efficiencies were $99 \%$. At the end of the synthesis, supports were treated with concentrated ammonia at $55^{\circ} \mathrm{C}$ for $16 \mathrm{~h}$. Oligonucleotides were purified using $\mathrm{COP}^{\mathrm{TM}}$ cartridges. After purification, products were analysed by analytical HPLC. In both cases, a major peak was obtained that was isolated and characterized by MS (see below and Table 1). Overall (synthesis and purification) yields were $14 \%$ for both supports. We, therefore, concluded that both supports are equally effective for the preparation of 3-amino tailed oligonucleotides.

The dodecamer R5 (Table 1) was then prepared using DMT-O- $\left(\mathrm{CH}_{2}\right)_{6}$ NH-NPEOC-CPG produced by activation with CDI and NPC and using DMT-O$\left(\mathrm{CH}_{2}\right)_{6}-\mathrm{NH}-\mathrm{FMOC}-\mathrm{CPG}$. It has recently been shown that $\mathrm{R} 5$ is a powerful inhibitor of the proliferation of human cell lines, which have been transformed with the mutated Ha-ras gene. 2' After synthesis, deprotection, and cartridge purification, HPLC analysis of the product coming from the NPEOC linker showed a major component with the expected molecular mass. The product obtained from the FMOC linker consisted of a major component (50-60\%) with the expected retention time and molecular weight together with other small components. We tried to characterize the more abundant of the side products (retention time $15.6 \mathrm{~min}, 20-30 \%$ of total), but we could not obtain the mass spectra. The highest overall yield $(12 \%)$ was obtained from the synthesis using the NPEOC linker prepared by activation with CDI (Table 1 ).

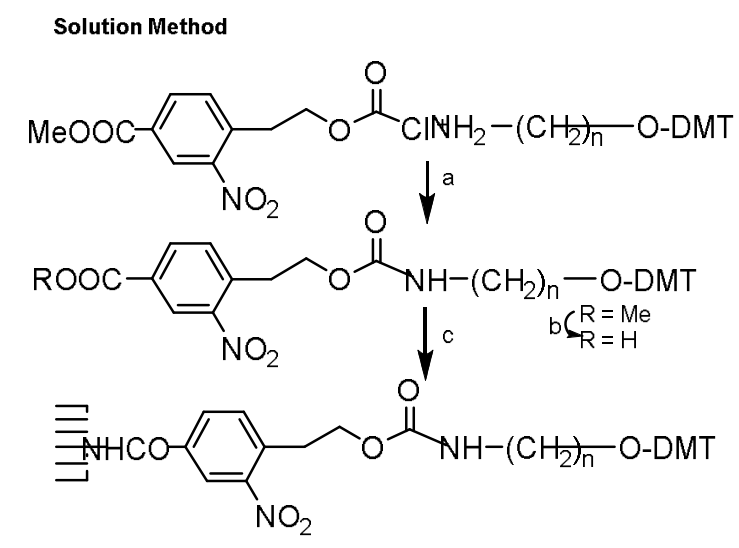

Solid-phase Method

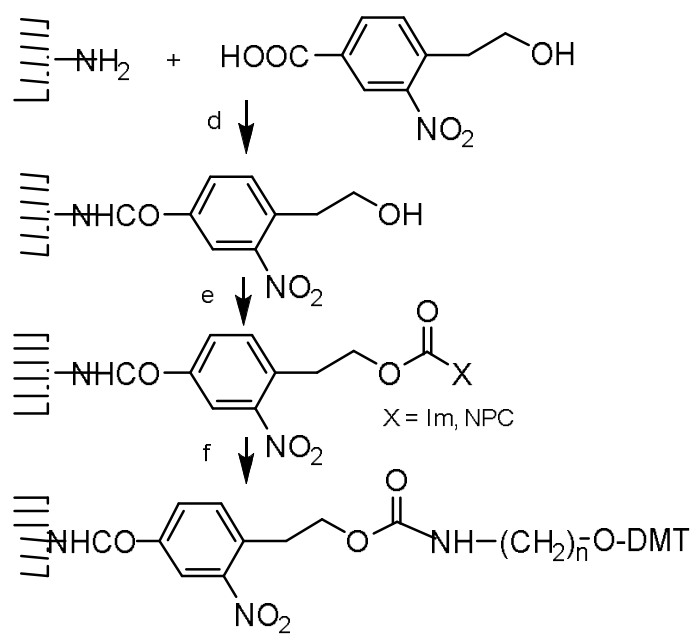

Figure 4. Outline of the different methods used for the preparation of solid supports. Solution method: (a) chloroformate, compound 3, DMAP; (b) $\mathrm{NaOH}$, dioxane, methanol; (c) carboxylic acid, DCC, HOBt, LCAA-CPG. Solid-phase method: (d) carboxylic acid, DCC, HOBt, LCAA-CPG; (e) CDI or NPC; (f) compounds 1-3. 
It was observed that a small amount of DMT (10-15\% of total) was still present on the supports after ammonia treatment. For this reason an alternative deprotection protocol was studied. Dodecamer R5 was prepared on DMT-O- $\left(\mathrm{CH}_{2}\right)_{3}-\mathrm{NH}-\mathrm{NPEOC}-\mathrm{CPG}$. After synthesis, half of the support was treated with ammonia and the other half was treated with $0.5 \mathrm{M} \mathrm{DBU}$ in pyridinc at room temperature for $16 \mathrm{~h}$. The solid support was filtered and the filtrates neutralized and concentrated to dryness. Oligonucleotide was separated from DBU using a Sephadex column and the fraction containing the oligonucleotide was concentrated to dryness and treated with ammonia. Although the support coming from the DBU treatment was completely free of the DMT (indicating a more efficient release of oligonucleotide), the overall yield was lower ( $9 \%)$ than the yield obtained with the standard ammonia treatment $(14 \%)$. This is due to the increased number of manipulations that is needed in the DBU-ammonia deprotection protocol.

Table 1. Sequences prepared in this work

\begin{tabular}{|c|c|c|c|c|c|c|}
\hline Sequence & Solid support" & Deprotection" & Yicld & $\mathrm{MS}(\mathrm{Da})^{\mathrm{a}}$ & $\begin{array}{l}\text { Expected } \\
\text { mass }\end{array}$ & $\begin{array}{r}\text { HPLC } \\
(\min )\end{array}$ \\
\hline A $5^{\prime}$ CCGACC-phosphate- $\left(\mathrm{CH}_{2}\right)_{0}-\mathrm{NH}_{2}$ & NPEOC, CDI & $\mathrm{NH}_{2}$ & $14 \%$ & n.d. & 1913.3 & 13.3 \\
\hline & NPEOC, solution & $\mathrm{NH}_{3}$ & $14 \%$ & 1912.1 & 1913.3 & 13.3 \\
\hline B (R5N6) 5' CACCGACGGCGC-phosphate- $\left(\mathrm{CH}_{2}\right)_{6}-\mathrm{NH}_{2}$ & NPEOC, CDI & $\mathrm{NH}_{3}$ & $12 \%$ & 3794.1 & 3794.5 & 15.0 \\
\hline B & NPEOC, NPC & $\mathrm{NH}$, & $9 \%$ & n.d. & 3794.5 & 14.9 \\
\hline B & FMOC, CDI & $\mathrm{NH}_{3}$ & $7 \%$ & 3794.5 & 3794.5 & $14.8 / 15.6$ \\
\hline $\mathrm{C}(\mathrm{R} 5 \mathrm{~N} 3) 5^{\prime} \mathrm{CACCGACGGCGC}$-phosphate- $\left(\mathrm{CH}_{2}\right),-\mathrm{NH}$, & NPEOC, CDI & $\mathrm{NH}_{3}$ & $14 \%$ & n.d. & 3753.6 & 15.8 \\
\hline 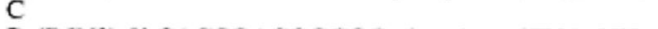 & NPEOC, CDI & $\mathrm{DBU}, \mathrm{NH}_{3}$ & $9 \%$ & $375,3,1$ & 3753,6 & 15.6 \\
\hline D (R5N2) 5' CACCGACGGCGC-phosphate- $\left(\mathrm{CH}_{2}\right)_{2}-\mathrm{NH}_{2}$ & NPEOC, CDI & $\mathrm{NH}$ & $14 \%$ & 3739.0 & 3739.0 & 14.2 \\
\hline $\mathrm{E}\left(\mathrm{R}^{2} \mathrm{C}_{\mathrm{NH}_{2}}\right) 5^{\prime} \mathrm{CACCGACGGCGCC_{ \textrm {NH } }}$ & NPEOC, CDI & $\mathrm{NH}_{3}$ & $16 \%$ & 3904.0 & 3903.8 & 15.8 \\
\hline $\mathrm{F}\left(\mathrm{R}^{2} \mathrm{U}_{\mathrm{NH}_{2}}\right)$ 5'CACCGACGGCGCU $_{\mathrm{NH}_{z}}$ & NPEOC, CDI & $\mathrm{NH}_{3}$ & $15 \%$ & 3905.2 & 3904.6 & 15.4 \\
\hline
\end{tabular}

aType of linker used between solid support and the amino function and method used for the preparation of the solid support. NPEOC: ( $p-$ nitrophenyl) ethoxycarbonyl; FMOC: 9-fluorenylmethoxycarbonyl. CDI: activation with carbonyl diimidazole. NPC: activation with $p$-nitrophenyl chloroformate.

${ }^{b}$ Final deprotection. $\mathrm{NH}_{3}$ standard ammonia deprotection. $\mathrm{DBU}, \mathrm{NH}_{3}$ : two step deprotection using 0.5 M DBU in pyridine and after standard ammonia treatment.

'Overall yield after synthesis and HPLC purification.

dMeasured mass using electrospray.

${ }^{\mathrm{e}}$ Retention time of the major peaks observed in HPLC (see conditions in experimental); n.d.: not determined.

Finally, dodecamer R5 having aminoethanol, 3'-amino- 2',3'dideoxycytidine and 3'-amino-2',3'-dideoxyuridine at the 3'-end was prepared with the appropriate NPEOC supports prepared by the 'CDI solidphase method' and using the standard ammonia deprotection (Fig. 5 and Table 1). Moreover, dodecamer R5 carrying a 2-deoxy-1,4-anhydro-D-ribitol molecule at the 3' end was prepared for comparative purposes. The corresponding support (Fig. 5) was prepared from the appropriate DMTprotected derivative (22) using the standard succinyl linker. 


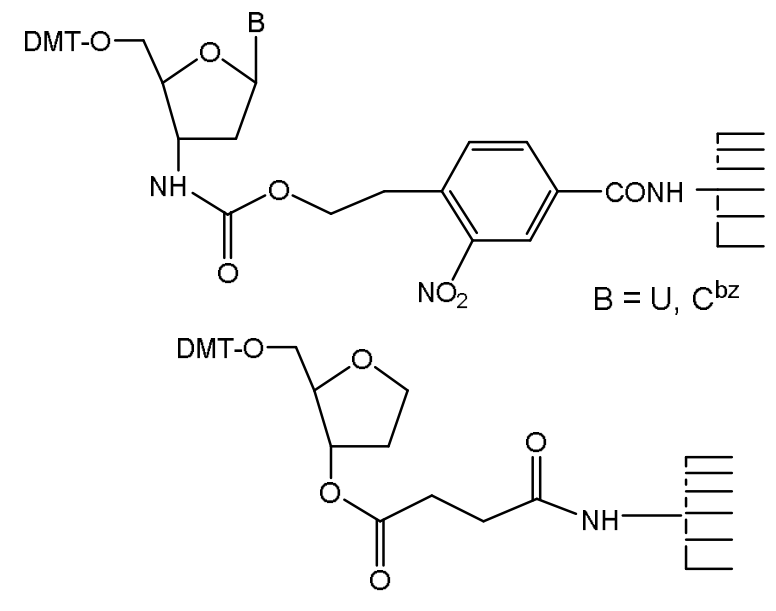

Figure 5. Structure of solid supports carrying 3'-amino-2',3' dideoxynucleosides and 2-deoxy-I,4-anhydro-D-ribitol molecules.

\section{Characterization of modified oligonucleotides by EIMS}

Modified oligonucleotides are usually characterized by enzyme digestion and HPLC analysis of the components. Due to exonuclease stability and the poor UV-absorption characteristics of some of the amino derivatives, this technique is not suitable for the characterization of 3'amine-tailed oligonucleotides. The last years have seen important developments in MS, especially for protein characterization (23). The high sensitivity achieved allows modified oligonucleotides to be routinely analysed. We have used a nanoelectrospray device developed in our laboratory $(24,25)$ to characterize 3'-amine-tailed oligonucleotides. Figure 6 (A) shows a classical electrospray spectrum with its series of multiply charged ions. The peaks can be deconvoluted into a single peak displaying the neutral mass of the oligonucleotide [Fig. 6 (B)]. The spectrum was obtained using only $15 \mu \mathrm{g}$ of the oligonucleotide. All oligonucleotides discussed in this paper were characterized using this technique (Table 1 ).
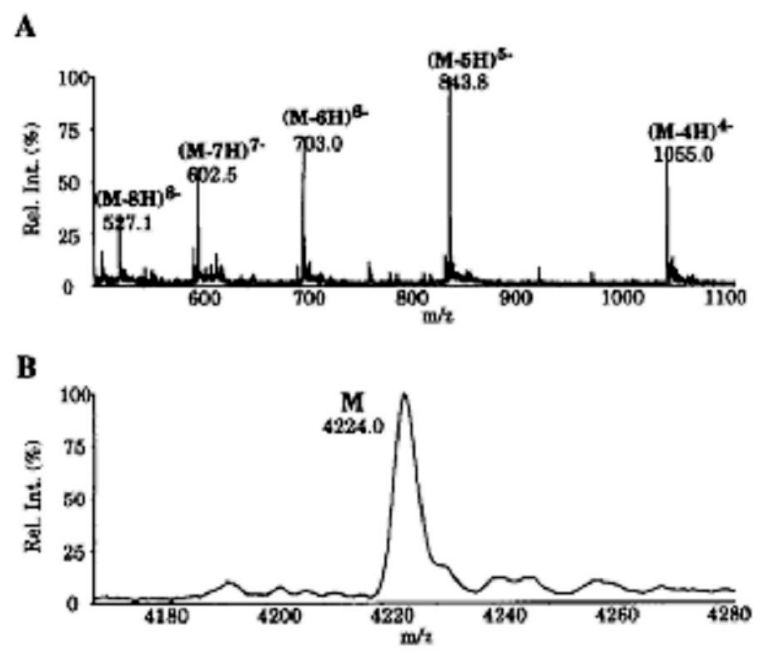

Figure 6. MS analysis of oligonucleotide R5 labeled with fluoresceine. The figure shows the original electrospray spectrum (A) and the derived deconvulation (B) of a synthetic oligonucleotide. The oligonucleotide R5 labeled with fluoresceine was dissolved to a concentration of $70 \mathrm{pmol} / \mu \mathrm{L}$ in water. $0.5 \mu \mathrm{L}$ of the stock solution were mixed with $10 \mu \mathrm{L}$ of a $2.5 \%$ 
ammonia $1: 1$, water:methanol solution. One $\mu \mathrm{L}$ of the final solution (3.5 $\mathrm{pmol} / \mu \mathrm{L}$ ) was filled into the NanoES source and the spectrum acquired.

Table 2. Properties of 3'-amino-modified oligonucleotides: oligonucleotide degradation by snake venom phosphodiesterase and melting temperatures of duplexes containing 3'-modified oligonucleotides

\begin{tabular}{|c|c|c|c|c|c|c|c|}
\hline & R5 & R5N2 & $\mathrm{R} 5 \mathrm{~N} 3$ & R5N6 & $\mathrm{R} 5 \mathrm{C}_{\mathrm{N} \mathrm{H}_{2}}$ & $\mathrm{R} \mathrm{U}_{\mathrm{N} 11:}$ & R5rib \\
\hline$k\left(\min ^{-1}\right)$ & 0.025 & 0.0011 & 0.00038 & 0.00073 & 0.0043 & 0.0025 & 0.00042 \\
\hline$t_{1, z}(\mathrm{~h})$ & 0.46 & 10.5 & 30.6 & 27.8 & 2.7 & 4.7 & 27.8 \\
\hline Stability & 1 & 23 & 67 & 61 & 6 & 10 & 61 \\
\hline$T_{m}\left({ }^{\circ} \mathrm{C}\right)^{x}$ & 69.0 & 69.5 & 70.3 & 69.1 & 70.8 & 69.6 & 69.8 \\
\hline
\end{tabular}

a Melting experiments were performed in $0.15 \mathrm{M} \mathrm{NaCl}, 0.05 \mathrm{M}$ Tris $-\mathrm{HCl} \mathrm{pH}$ 7.5. Complementary sequence: 3' GTGGCTGCCGCG 5' except for $\mathrm{R}^{2} \mathrm{C}_{\mathrm{NH} 2}$ that was: 3' GTGGCTGCCGCGG 5'; and for $\mathrm{R}^{\prime} \mathrm{U}_{\mathrm{NH} 2}$ that was: 3' GTGGCTGCCGCGA 5'

\section{Hybridization properties and exonuclease resistance of 3'-amine tailed oligonucleotides}

The effect of the modification on the 3'-end on the hybridization properties of the oligonucleotides was measured by determination of the melting temperatures of DNA-duplexes made of the 3'-modified oligonucleotides and their complementary sequences. Melting temperatures are shown in Table 2 and they all are similar or slightly higher than the melting temperature of the duplex made with unmodified oligonucleotides. This indicates that the modifications at the 3'-end that we have prepared have very little influence on the hybridization properties of the oligonucleotide.

The stability towards exonuclease degradation of 3' modified oligonucleotides was studied by recording the UV absorbance at $260 \mathrm{~nm}$ during the incubation of oligonucleotides with snake venom phosphodiesterase at $37^{\circ} \mathrm{C}$. An increase on the UV absorbance of the solution is observed due to the release of the nucleotides from the oligonucleotide. From these curves the rate constant can be calculated assuming a first-order kinetic. Table 2 shows the values obtained for dodecamers R5 having different groups at the 3'-end. Unmodified R5 was degraded in $1 \mathrm{~h}$ ( $\left.\mathrm{t}_{1 / 2}=0.46 \mathrm{~h}\right)$, while 3 '-modified oligonucleotides showed a higher stability. Oligonucleotides having 3'-amino-2',3'- dideoxynucleosides at the 3 '-end were approximately 10 times more stable. Similar results were described for oligonucleotides having 3'-amino-2',3'-dideoxythymidine (10). The dodecamer having the 2-aminoethyl group (R5N2) at the $3^{\prime}$-end was 20 times more stable and clearly the most stable oligonucleotides were dodecamers having 3-aminopropyl (R5N3), 6-aminohexyl (R5N6), and the ribitol (R5rib), which were 60 times more stable. The stability found in these compounds is in agreement with previous reports $(3,26,27)$.

\section{Preparation of oligonucleotide conjugates using 3'-amine tailed oligonucleotides}

The use of 3'-amine tailed oligonucleotides for the preparation of oligonucleotide conjugates was demonstrated with dodecamers R5N6 and R5N3. Reaction of dodecamer having the 3'-aminopropyl at the 3'-end with fluorescein-4(5)-carboxamidocaproic acid N-succinimidyl ester at $\mathrm{pH} 9.0$ yielded the fluoresceine labeled oligonucleotide ( $70 \%$ conversion) that was 
purified (recovery 47\%) and characterized by UV-vis and MS. Furthermore, reaction of dodecamer having the 6-aminohexyl group with dexamethasone succinic acid $\mathrm{N}$-succinimidyl ester (28) yielded the desired oligonucleotidedexamethasone conjugate (65\% conversion) that was purified (recovery $40 \%)$ and characterized by MS.

\section{Discussion}

There is an increasing interest in oligonucleotides containing different amino groups at the 3 '-end due to their increased resistance towards exonucleases and the special reactivity of the amino function (1, 13-27). The applications of these oligonucleotides are dependent on the availability of versatile and efficient methodologies to prepare them. In this report we have described the preparation of new solid supports that allow the synthesis of these Y-modified oligonucleotides. Two different base labile linkers have been studied. Best results in terms of degree of functionalization, yields, and purity of the products were obtained with supports based on the o-nitrophenylethyl group. A support containing the fluorenylmethyl group yielded less and more of heterogeneous product. Although we could not characterize the observed side products, we believe that the FMOC linker is probably not completely stable to the conditions encountered during the preparation of the support/during oligonucleotide synthesis. The most convenient method for the preparation of the supports has been the successive addition of the components (linker, carbonyl group and amine derivative) to the support ('solid-phase method'). Unfortunately, the coupling of the more hindered 3'-amino-2',3'-dideoxynucleosides is less efficient and in these cases supports with low loadings are obtained.

The preparation of 3'-amino oligonucleotides has been described using the standard succinyl linkage (5-8). For that purpose a special aminodiol is needed. The first alcohol is needed to attach the derivative to the CPG using the standard succinyl group and the second alcohol is needed to build the oligonucleotide sequence. The amino group should be protected with base-labile groups (FMOC). Also, special phthalimido linkers have been designed for the preparation of 3'-amino-tailed oligonucleotides (3-11). However, the preparation of these phthalimido derivatives is long and phthalimido linkers could be only used for primary amino groups. Other linkers such as phosphoramidate $(9,10)$, glycolic and 4-hydroxybutyric (12), and dithioethoxycarbonyl (13) need special deprotection protocols to obtain the desired 3'-amino oligonucleotide. Compared with existing supports the method described here is simple and versatile, because it could be adapted to any amino derivative. The NPEOC linker could be easily obtained starting from commercially available 4-aminophenethyl alcohol (four steps, $30 \%$ overall yield) (15). 3'-Modified oligonucleotides could be obtained using standard ammonia deprotection conditions or using a nonnucleophilic base such as DBU (15). We have observed that the release of the 3'-amino oligonucleotide from the NPEOC supports is high (around $85 \%$ ), but it is not completed after an overnight treatment at $55^{\circ} \mathrm{C}$. Use of DBU for the deprotection improves the release of oligonucleotide, but increases the number of manipulations. Therefore, standard ammonia deprotection is preferred.

An important part of the preparation of modified oligonucleotides is the characterization of the products. The control of the DMT release during 
the synthesis and the chromatographic or electrophoresis data are not enough to demonstrate the correct incorporation and release of the 3'amino oligonucleotide. Enzyme digestion and HPLC analysis of the components can lead to wrong interpretations with nuclease resistant oligonucleotides. Mass spectrometry using a special nanoelectrospray device and quadropole detectors was found to be very suitable for the characterization of these modified oligonucleotides. Oligonucleotide molecular weights could be determined with high precision with very small amounts of material coming from the HPLC purification.

Oligonucleotide bearing amine derivatives at the 3 '-end have been shown to hybridize with complementary sequences with the same or slightly higher affinity, but they are much more resistant to degradation by snake venom phosphodiesterase $(3,26)$. These properties make them good candidates for antisense studies.

Moreover, due to the singular reactivity of the amino alkyl group, the amino modified oligonucleotides are useful intermediates for nonradioactive labeling and for the preparation of conjugates with lipids that may facilitate cellular uptake. The method described could be adapted not only for the incorporation of amino derivatives at the 3 '-end of oligonucleotides, but also for the incorporation of amino derivatives in peptides and other compounds.

\section{Experimental}

\section{General methods}

All reactions were carried out in oven-dried glassware, under a nitrogen or argon atmosphere. Except when water was present in the reaction, at the beginning of the reaction the starting compounds were dried by coevaporation with dry solvents. At the end of the reactions, the standard work up was as follows: The reaction mixture was concentrated to dryness. The residue was dissolved in $\mathrm{CH}_{2} \mathrm{Cl}_{2}$ or $\mathrm{CHCl}_{3}$ and washed with the following aq solns: $5 \% \mathrm{NaHCO}_{3}$ and satd $\mathrm{NaCl}$. The organic phase was dried with sodium sulfate and concentrated to dryness. Oligonucleotide syntheses were performed on a ABI 392 DNA synthesizer. LCAA-CPG was from CPG Inc (New Jersey). Nucleoside $\left(\mathrm{dA}^{\mathrm{bz}}, \mathrm{dC}^{\mathrm{bz}}, \mathrm{dG} \mathrm{G}^{\mathrm{ibu}}\right.$, and $\left.\mathrm{T}\right)$ phosphoramidites and solutions needed for oligonucleotide synthesis were from Cruachem Ltd (Glasgow, Scotland). The remaining reagents were purchased from Aldrich Chemical Co (Milwaukee, Wisconsin) and Fluka Chemie AG (Buchs, Switzerland). Dry solvents and silica gel for column chromatography (70230 mesh) were from S.D.S. (Peypin, France). Analytical TLC was carried out on aluminium-backed Merck $60 \mathrm{~F}_{254}$ silica plates. Compounds were visualized by UV shadowing and, in the case of compounds containing DMT groups, by exposure to hydrochloric acid fumes. HPLC analyses were performed on a Waters chromatograph. NMR spectra were recorded on a Varian-Geminis FT-200 and a Varian XL-300 spectrometers. Thermal dissociation curves, UV spectra and phosphodiesterase degradation curves were obtained on a Shimadzu UV-2101 equipped with a pelltier temperature controller.

Synthesis of 1-0-dimethoxytrityl-6-amino-1-hexanol (3), 1-0dimethoxytrityl-3-amino-1-propanol (2) and 1-0-dimetoxytrityl-2amino-1-ethanol (1). 6-Chloro- 1-hexanol (1 g, $7.3 \mathrm{mmol}$ ) was dissolved 
in $50 \mathrm{~mL}$ of DMF. To the solution $1.5 \mathrm{~g}(8.1 \mathrm{mmol})$ of potassium phthalimide were added. The mixture was heated at $6^{\circ} \mathrm{C}$ for $4 \mathrm{~h}$ with magnetic stirring. The reaction mixture was cooled at room temperature and a white precipitate of potassium chloride was observed and filtered out. The solution was concentrated to dryness and the residue was treated as described in the standard work up obtaining $1.5 \mathrm{~g}$ of $6-\mathrm{N}$-phthatoyl- 6-amino-1-hexanol (71\% yield). ${ }^{1} \mathrm{H} \mathrm{NMR}\left(\mathrm{CDCl}_{3}, 200 \mathrm{MHz}\right): \delta 7.82(\mathrm{~m}, 2 \mathrm{H}), 7.73(\mathrm{~m}, 2 \mathrm{H})$, 3.69-3.62 $(2 \mathrm{t}, 4 \mathrm{H}), 1.6-1.3(\mathrm{~m}, 8 \mathrm{H})$. A similar protocol was used for the preparation of 3-N-phthaloyl-3-amino-1-propanol (60\% yield) and $2-\mathrm{N}$ phthaloyl-2-amino-I-ethanol (63\% yield). ${ }^{1} \mathrm{H}$ NMR of these compounds were similar to that of aminohexanol derivative with the exception of the signal at 1.6-1.3 ppm that integrates $2 \mathrm{H}$ in the case of 3-N-phthaloyl-3-amino-1propanol and does not exist in the case of 2-N-phthaloyl-2-amino-1ethanol.

6-N-Phthaloyl-6-amino-1-hexanol $(1 \mathrm{~g}, 4.0 \mathrm{mmol}$ ) was dissolved in $20 \mathrm{~mL}$ of dry pyridine and $1.55 \mathrm{~g}(4.4 \mathrm{mmol})$ of DMT-C1 were added. After $16 \mathrm{~h}$ of magnetic stirring at room temperature, $0.5 \mathrm{~mL}$ of methanol was added and the mixture was concentrated to dryness. After standard work up, the product was purified by column chromatography on silica gel eluting with $\mathrm{CH} 2 \mathrm{Cl} 2$ obtaining the desired 1-O-DMT-6-N-phthaloyl- 6-amino-1-hexanol. Yield: $1.74 \mathrm{~g}, 78 \% .{ }^{1} \mathrm{H}$ NMR $\left(\mathrm{CDCl}_{3}, 200 \mathrm{MHz}\right): \delta 57.81(\mathrm{~m}, 2 \mathrm{H}), 7.72(\mathrm{~m}$, $2 \mathrm{H}), 7.4-7.2(\mathrm{~m}, 9 \mathrm{H}), 6.85(\mathrm{~d}, 4 \mathrm{H}), 3.79(\mathrm{~s}, 6 \mathrm{H}), 3.65(\mathrm{t}, 2 \mathrm{H}), 3.02(\mathrm{t}, 2 \mathrm{H})$, 1.6-1.3 $(\mathrm{m}, 8 \mathrm{H})$. A similar protocol was used for the preparation of 1-ODMT-3- $N$-phthaloyl- 3-amino-I-propanol (45\% yield) and 1-O-DMT- 2-Nphthaloyl-2-amino-l-ethanol (60\% yield). As described before, ${ }^{1} \mathrm{H}$ NMR of these compounds were similar to the aminohexanol derivative with the exception of the signal at 1.6-1.3 ppm that integrates $2 \mathrm{H}$ in the case of 1 O-DMT-3-N-phthaloyl-3-amino-1-propanol and does not exist in the case of 1-O-DMT- 2-N-phthaloyl-2-amino-1-ethanol.

1-O-DMT-6-N-phthaloyl-6-amino-1-hexanol $(0.46 \mathrm{~g}, 0.83 \mathrm{mmol})$ was dissolved in $10 \mathrm{~mL}$ of methanol and $0.04 \mathrm{~mL}$ of $\mathrm{NH}_{2}--\mathrm{NH}_{2} \cdot \mathrm{H}_{2} \mathrm{O}$ were added. After $16 \mathrm{~h}$ of magnetic stirring at room temperature, the mixture was filtered and the solution was concentrated to dryness. After standard work up, the product was purified by column chromatography on silica gel eluting with a 5-35\% methanol gradient in $\mathrm{CH}_{2} \mathrm{Cl}_{2}$ obtaining $100 \mathrm{mg}$ (30\%) of 1-ODMT-6-amino-1-hexanol. TLC (25\% methanol in $\left.\mathrm{CH}_{2} \mathrm{Cl}_{2}\right) \mathrm{R}_{\mathrm{f}} 0.25$. ${ }^{1} \mathrm{H}$ NMR $\left(\mathrm{CDCl}_{3}, 200 \mathrm{MHz}\right): 67.29(\mathrm{~m}, 9 \mathrm{H}), 6.82(\mathrm{~m}, 4 \mathrm{H}), 4.87$ (wide $\left.\mathrm{s}, 2 \mathrm{H}\right), 3.77$ $(\mathrm{s}, 6 \mathrm{H}), 3.01(\mathrm{t}, 2 \mathrm{H}), 2.77(\mathrm{t}, 2 \mathrm{H}), 1.59(\mathrm{~m}, 8 \mathrm{H}) .1$-O-DMT-3-amino-Ipropanol. TLC ( $25 \%$ methanol in $\left.\mathrm{CH}_{2} \mathrm{Cl}_{2}\right) \mathrm{R}_{\mathrm{f}} 0.24 .{ }^{1} \mathrm{H}$ NMR $\left(\mathrm{CDCl}_{3}, 200 \mathrm{MHz}\right)$ : $87.29(\mathrm{~m}, 9 \mathrm{H}), 6.82(\mathrm{~m}, 4 \mathrm{H}), 3.77(\mathrm{~s}, 6 \mathrm{H}), 3.16(\mathrm{t}, 2 \mathrm{H}), 2.88(\mathrm{t}, 2 \mathrm{H}), 1.86$ $(\mathrm{m}, 2 \mathrm{H})$. 1-O-DMT-2-amino-1-ethanol. TLC (25\% methanol in $\left.\mathrm{CH}_{2} \mathrm{Cl}_{2}\right) \mathrm{R}_{\mathrm{f}}$ 0.20. ${ }^{1} \mathrm{H}$ NMR $\left(\mathrm{CDCl}_{3}, 200 \mathrm{MHz}\right): \delta 7.29(\mathrm{~m}, 9 \mathrm{H}), 6.82(\mathrm{~m}, 4 \mathrm{H}), 3.77$ (s, $6 \mathrm{H}), 2.90(\mathrm{t}, 2 \mathrm{H})$.

5'-0-Dimethoxytrityl-2,3'-anhydro-2'-deoxyuridine (5). Adapted from the synthesis of the same thymidine derivative (17), $2.28 \mathrm{~g}$ of $\mathrm{dU}$ (10 $\mathrm{mmol}$ ) were reacted with $3.7 \mathrm{~g}$ of DMT-Cl $(11 \mathrm{mmol})$ in pyridine. After $3 \mathrm{~h}$ at room temperature, the reaction mixture was concentrated to dryness. After standard work up $5.24 \mathrm{~g}(9.87 \mathrm{mmol}, 99 \%)$ of DMT-dU were obtained. ${ }^{13} \mathrm{C} \mathrm{NMR}\left(\mathrm{CDCl}_{3}, 101 \mathrm{MHz}\right): 8163.7,158.6,150.5,144.2,140.2,135.3$, 
$135.2,130.0,128.0,127.7,127.0,113.2,102.1,86.7,86.1,85.1,71.4$, $63.0,55.1,41.1$.

The residue was dissolved in $30 \mathrm{~mL}$ of pyridine and the solution was cooled with ice. To the solution $2.6 \mathrm{~mL}$ of methanesulfonyl chloride $(33.2 \mathrm{mmol}$ ) were added dropwise and the resulting solution was allowed to stir overnight at $4{ }^{\circ} \mathrm{C}$. The reaction was quenched by the addition of water ( 1 $\mathrm{mL}$ ) followed by an additional $30 \mathrm{~min}$ of stirring. The mixture was poured into ice-water $(1.5 \mathrm{~L})$ with strong stirring and the resulting product was filtered and washed with water. Yield 95\%.

The product obtained above $(9.5 \mathrm{mmol})$ was dissolved into a solution containing $8.77 \mathrm{~g}(47.4 \mathrm{mmol})$ of potassium phthalimide in $140 \mathrm{~mL}$ of DMF and $40 \mathrm{~mL}$ of water. The mixture was heated to $95^{\circ} \mathrm{C}$ over $20 \mathrm{~min}$ and then cooled to room temperature. The mixture was poured slowly to ice-water $(1.5 \mathrm{~L})$. The white precipitate was filtered and washed with water. Yield $4.16 \mathrm{~g}(8.1 \mathrm{mmol}, 80 \%) .{ }^{13} \mathrm{C} \mathrm{NMR}\left(\mathrm{CDCl}_{3}, 101 \mathrm{MHz}\right): \delta 170.8,158.1,153.3$, $144.1,139.5,134.9,129.5,127.4,127.3,126.4,112.7,108.4,87.1,86.2$, 83.8, 76.8 (inside $\mathrm{CDC}_{3}$ signals), 61.6, 54.7, 33.0.

\section{5'-0 -Dimethoxytrityl-3'-azido-2',3'-dideoxyuridine (6).}

5'-O-DMT-2,3'-anhydro-2'-deoxyuridine $(4.16 \mathrm{~g}, 8.1 \mathrm{mmol})$ was dissolved in DMF and $1.2 \mathrm{~g}(24.3 \mathrm{mmol})$ of lithium azide were added. The mixture was heated at $135^{\circ} \mathrm{C}$ for $8 \mathrm{~h}$. The reaction was cooled at room temperature and solvents were removed. The residue was purified by silica gel chromatography. Yield $3.58 \mathrm{~g}(6.4 \mathrm{mmol}, 79 \%) .{ }^{13} \mathrm{C} \mathrm{NMR}\left(\mathrm{CDCl}_{3}, 101 \mathrm{MHz}\right)$ : $\delta 163.4,158.5,150.2,144.0,139.6,134.9,129.8,127.8,126.9,113.1$, $102.1,86.9,84.6,83.4,62.0,59.4,55.0,38.0$.

\section{5'-0-Dimethoxytrityl-4-0-(2-nitrophenyl)-3'-azido-2',3'-dideoxyuri-}

dine. 5'-O-DMT-3'-azido-2',3'-dideoxuridine (3 g, $5.4 \mathrm{mmol}$ ) was dissolved in dry $\mathrm{CH}_{2} \mathrm{Cl}_{2}$. To a solution of $4.2 \mathrm{~mL}(30 \mathrm{mmol}$ ) of triethylamine, $163 \mathrm{mg}$ $(1.34 \mathrm{mmol})$ of DMAP, and $1.76 \mathrm{~g}(8.08 \mathrm{mmol})$ of mesitylensulfonyl chloride were added. After 30 min of magnetic stirring at room temperature, $1.49 \mathrm{~g}$ (10.8 retool) of 2-nitrophenol and $120 \mathrm{mg}(1.07 \mathrm{mmol}) \quad 1,4$ diazabicyclo[2.2.2] octane were added and the mixture was stirred for $2 \mathrm{~h}$. After removal of the solvents and standard work up, the product was purified by column chromatography on silica gel eluting with petroleum ether: ethyl acetate $(1: 1)$. Yield $2.69 \mathrm{~g}(4 \mathrm{mmol}, 74 \%) .{ }^{13} \mathrm{C} \mathrm{NMR}\left(\mathrm{CDCl}_{3}\right.$, $101 \mathrm{MHz}): \delta 170.4,158.5,154.3,144.7,144.6,143.7,141.3,134.9$, $134.8,134.6,129.7,127.8,126.9,126.4,125.6,125.2,113.1,94.2,87.1$, $86.9,86.3,83.8,61.3,58.4,54.9,38.5$.

5'-0-Dimethoxytrityl-3'-azido-2',3'-dideoxycytidine (8). 5 '-O-DMT-4O-( 2-nitrophenyl )- 3 '-azido- 2',3 '-dideoxyuridine $(2.3 \mathrm{~g}, 3.4 \mathrm{mmol})$ was dissolved in dioxane and the solution was installed on a stainless steel bomb. Ammonia was distilled on the bomb and the reaction was heated at $60^{\circ} \mathrm{C}$ for 2 days. The bomb was cooled to room temperature and ammonia was released slowly. The resulting mixture was transferred to a roundbottom flask together with successive washings with a $20 \%$ methanol solution in $\mathrm{CH}_{2} \mathrm{Cl}_{2}$. The product was purified by silica gel. Yield: $1.6 \mathrm{~g}$ (2.9 $\mathrm{mmol}, 85 \%) .{ }^{13} \mathrm{C} \mathrm{NMR}\left(\mathrm{CDCl}_{3}, 101 \mathrm{MHz}\right): \delta$ 165.9, 158.4, 155.7, 144.2, 
139.7, 135.0, 129.8, 127.7, 126.7, 113.0, 94.8, 86.6, 85.3, 83.1, 61.9, $59.2,54.9,38.3$.

5'-O-Dimethoxytrityi-N4-benzoyl.3 '-azido-2',3'-dideoxycytidine (9). 5'-O-DMT-3'-azido-2',3'-dideoxycytidine $(1.6 \mathrm{~g}, 2.9 \mathrm{mmol})$ was dissolved in $20 \mathrm{~mL}$ of pyridine and $0.39 \mathrm{~mL}(3.77 \mathrm{mmol})$ of benzoyl chloride were added. After $1 \mathrm{~h}$ of magnetic stirring at room temperature, the solvents were concentrated. After standard work up, the product was purified on silica gel eluting with a 0 to $5 \%$ methanol gradient in $\mathrm{CH}_{2} \mathrm{Cl}_{2}$. Yield $90 \% .{ }^{13} \mathrm{C}$ $\operatorname{NMR}\left(\mathrm{CDCl}_{3}, 101 \mathrm{MHz}\right): \delta 166.4,162.3,158.5,154.5,144.3,143.8,130.5$, $134.9,132.9,129.8,129.7,128.7,127.8,127.5,127.0,113.2,96.4,87.0$, $86.4,83.9,61.4,58.4,55.0,38.8$.

\section{5'-O-DimethoxytrityI-N4-benzoyl-3'-amino-2',3'-dideoxycytidine} (10) and 5'-0-dimethoxytrityl-3'-amino-2',3'- dideoxyuridine (7). DMT-3'-azido-dideoxynucleosides (6 and 9, $0.2 \mathrm{mmol}$ ) were treated with polymer supported triphenylphosphine (Fluka, $0.33 \mathrm{~g}$ loading $3 \mathrm{mmol}$ per $\mathrm{g}$ ) as described (20).

\section{Preparation of the solid support loaded with the 6- O-DMT-6- hydroxyhexylaminocarbonyloxy-o-nitrophenylethyl group using the solution method}

Preparation of 4-[2-(6-0-dimethoxytrityl-6-hydroxy- 1-hexylamino) carbonyloxyethyl] -3-nitrobenzoate methyl ester. 1-O-DMT-6-amino-Ihexanol (105 mg, $0.25 \mathrm{mmol}$ ) and DMAP (46 mg, $0.34 \mathrm{mmol}$ ) were dissolved in $10 \mathrm{~mL}$ of dry $\mathrm{CH}_{2} \mathrm{Cl}_{2}$ and the mixture was cooled with an icebath. To the solution $104 \mathrm{mg}(0.34 \mathrm{mmol})$ of 2-[4-(methoxycarbonyl)-2nitrophenyl]ethyl chloroformate (15) was added. After 30 min of magnetic stirring at $0{ }^{\circ} \mathrm{C}$, the solution was left for $1 \mathrm{~h}$ at room temperature. The solution was concentrated to dryness and the residue was purified by column chromatography on silica gel eluting with a $50-80 \% \mathrm{CH}_{2} \mathrm{Cl}_{2}$ gradient in hexane. Yield $80 \mathrm{mg}(40 \%)$. TLC $\left(\mathrm{CH}_{2} \mathrm{Cl}_{2}\right.$ : hexane, $\left.1: 1\right) \mathrm{R}_{\mathrm{f}} 0.5$. ${ }^{1} \mathrm{H} \mathrm{NMR}$ $\left(\mathrm{CDCl}_{3}, 200 \mathrm{MHz}\right): \delta 8.60(\mathrm{~s}, 1 \mathrm{H}), 7.8(\mathrm{~d}, 1 \mathrm{H}), 7.46(\mathrm{~d}, 1 \mathrm{H}), 7.29(\mathrm{~m}, 9 \mathrm{H})$, $6.80(\mathrm{~m}, 4 \mathrm{H}), 4.46(\mathrm{t}, 2 \mathrm{H}), 3.95(\mathrm{~s}, 3 \mathrm{H}), 3.77(\mathrm{~s}, 6 \mathrm{H}), 3.33(\mathrm{t}, 2 \mathrm{H}), 2.80(\mathrm{t}$, $2 \mathrm{H}), 1.6-1.2(\mathrm{~m}, 6 \mathrm{H})$.

Hydrolysis of the methyl ester. 4-[2-(6-0-DMT-6- hydroxy-Ihexylamino)carbonyloxyethyl]-3-nitrobenzoate methyl ester (50 mg, 0.063 mmol) was dissolved in $3.2 \mathrm{~mL}$ of acetonitrile and $6.3 \mathrm{~mL}$ of a $0.05 \mathrm{M} \mathrm{NaOH}$ solution in water:dioxane (1:1) was added. After 5 min of magnetic stirring at room temperature the solution was neutralized by addition of $0.018 \mathrm{~mL}(0.31 \mathrm{mmol})$ of acetic acid and concentrated to dryness. The residue was dissolved in $30 \mathrm{~mL}$ of a $5 \%$ methanol solution in $\mathrm{CH}_{2} \mathrm{Cl}_{2}$ and the organic solution washed twice with $30 \mathrm{~mL}$ of a $10 \%$ citric acid soln. The organic phase was dried and concentrated to dryness to yield $40 \mathrm{mg}$ of the desired handle ( $80 \%$ yield). TLC (10\% methanol: $\left.\mathrm{CH}_{2} \mathrm{Cl}_{2}\right) \mathrm{R}_{\mathrm{f}} 0.45$. The proton NMR is identical to the starting material except for the absence of the signal at $3.95 \mathrm{ppm}$ (methyl ester).

Preparation of the solid support. The product obtained was used directly for the functionalization of the CPG solid support. The handle acid (40 mg, 
$0.05 \mathrm{mmol}$ ) was dissolved in DMF together with $6.9 \mathrm{mg}$ of HOBt and 13.2 $\mathrm{mg}$ of DCC. After $10 \mathrm{~min}$ on ice the mixture was added to $200 \mathrm{mg}$ of long amino alkyl CPG $(71 \mu \mathrm{mol} / \mathrm{g})$. The mixture was left at room temperature overnight with occasional mixing. The suspension was filtered and washed with DMF and acetonitrile. Unreacted amino groups were acetylated by treatment of the support with a $10 \%$ acetic anhydride solution in pyridine for $30 \mathrm{~min}$. Finally, the support was exhaustively washed with acetonitrile and dried. Loading was $10 \mu \mathrm{mol}$ of DMT groups per $\mathrm{g}$.

Preparation of solid supports with amino derivatives connected through base-labile linkers using the solid phase method

(a) Functionalization of CPG with the 4-(2-hydroxyethyl)- 3nitrobenzoic acid and the $\mathbf{N}$-[9-(hydroxymethyl)- 2-fluorenyl] succinamic acid. 4-(2-Hydroxyethyl)-3-nitrobenzoic acid (15) (12 mg, $0.057 \mathrm{mmol})$, HOBt $(9.6 \mathrm{mg}, 0.057 \mathrm{mmol})$, and DCC (11.7 mg, 0.057 $\mathrm{mmol}$ ) were dissolved in $5 \mathrm{~mL}$ of DMF and the solution was kept on ice for 10 rain. The resulting mixture was added to $0.4 \mathrm{~g}$ of long aminoalkyl CPG $(71 \mu \mathrm{mol} / \mathrm{g})$. The reaction was left at room temperature with occasional mixing. After $16 \mathrm{~h}$ the support gave a negative ninhydrin test and the suspension was filtered. The resulting support was washed with DMF, $\mathrm{CH}_{2} \mathrm{Cl}_{2}$, and acetonitrile, and dried. A similar protocol was used for the incorporation of $\mathrm{N}$-[9-(hydroxymethyl)-2-fluorenyl] succinamic acid (16).

\section{(b) Activation of the hydroxyl function of the solid supports functionalized with the o-nitrophenylethanol and the 9- fluorenylmethanol groups}

(I) Using 1,1-carbonyl diimidazole. CPG $(0.1 \mathrm{~g})$ loaded with the 2-(onitrophenyl)ethanol or the 9-fluorenylmethanol groups were treated with a solution of $16.2 \mathrm{mg}$ of CDI in $1 \mathrm{~mL}$ of acetonitrile. After $4 \mathrm{~h}$ at room temperature the supports were filtered and washed with dry acetonitrile and dried.

(II) Using p-nitrophenyl chloroformate. CPG $(0.2 \mathrm{~g})$ loaded with the onitrophenylethanol group were treated with a solution of $86.2 \mathrm{mg}(0.42$ $\mathrm{mmol}$ ) of NPC in $1 \mathrm{~mL}$ of acetonitrile. After $16 \mathrm{~h}$ at room temperature the supports were filtered and washed with dry acetonitrile and dried.

\section{(c) Functionalization of solid supports with the amino}

derivatives. Activated solid supports $(0.1 \mathrm{~g})$ were treated with a solution of $0.07 \mathrm{mmol}$ (30 mg) of 1-O-DMT-6-amino-I-hexanol dissolved in $1 \mathrm{~mL}$ of acetonitrile. After $16 \mathrm{~h}$ at room temperature the suspensions were filtered and the solid supports washed with acetonitrile, $\mathrm{CH}_{2} \mathrm{Cl}_{2}$ and acetonitrile, and dried. The resulting solid supports were treated with $2 \mathrm{~mL}$ of a $5 \% \mathrm{n}$ butylamine solution in acetonitrile in order to block the activated hydroxyl groups that did not react with the desired amino derivative. The solid supports were washed with acetonitrile and treated with a $10 \%$ acetic anhydride solution in pyridine for $30 \mathrm{~min}$. This treatment was designed to block hydroxyl groups that were not activated with CDI or NPC. After capping the solid supports were washed extensively with acetonitrile and dried. Functionalization of the supports were analyzed by measurement of 
the absorbance of the DMT cation released when a known amount of support was treated with acid solutions. Loadings were as follows: DMT-O$\left(\mathrm{CH}_{2}\right)_{6}$-NHNPEOC- CPG via activation with CDI: $20 \mu \mathrm{mol} / \mathrm{g}$; the same support obtained by activation with NPC: $13 \mu \mathrm{mol} / \mathrm{g}$. DMT-O- $\left(\mathrm{CH}_{2}\right)_{6}-\mathrm{NH}-$ FMOC-CPG via activation with CDI $14 \mu \mathrm{mol} / \mathrm{g}$.

The rest of the supports containing other amino derivatives were prepared using the NPEOC linker and the activation with CDI. Loadings were as follows: DMT-O- $\left(\mathrm{CH}_{2}\right)_{3}-\mathrm{NH}-\mathrm{NPEOC}-\mathrm{CPG}$ : $20 \mu \mathrm{mol} / \mathrm{g}$; DMTO- $\left(\mathrm{CH}_{2}\right)_{2}-\mathrm{NH}-$ NPEOC-CPG: $23 \mu \mathrm{mol} / \mathrm{g} ; \quad$ 5'-O-DMT- 3'-amino-ddC ${ }^{\mathrm{bz}}-\mathrm{NH}-\mathrm{NPEOC}-\mathrm{CPG}: 6$ $\mu \mathrm{mol} / \mathrm{g}$ and 5 '-O-DMT-3'-amino-ddU-NH-NPEOC-CPG: $5 \mu \mathrm{mol} / \mathrm{g}$.

\section{Oligonucleotide synthesis and purification}

Sequences A: 5'CACCGACGGCGC3' and B: 5'CCGACC3' were assembled using the solid supports and the appropriate protected nucleoside phosphoramidites on an automatic DNA synthesizer. The standard $1 \mu \mathrm{mol}$ scale synthesis cycle was used. In all cases the last DMT group was left to help purification. Coupling efficiencies were $99 \%$.

Deprotection of oligonucleotide supports were as follows: (a) standard deprotection; the supports were treated with $2 \mathrm{~mL}$ of a concentrated ammonia solution ( $32 \%$ ) at $55^{\circ} \mathrm{C}$ for $16 \mathrm{~h}$. The solution was filtered and the support washed with water. The combined filtrates were used directly if purification was performed using $\mathrm{COP}^{\mathrm{TM}}$ cartridges; and (b) two-steps deprotection: the supports were treated with a $0.5 \mathrm{M}$ DBU solution in pyridine $(2 \mathrm{~mL})$ at room temperature for $16 \mathrm{~h}$. The support was washed with pyridine and water. The combined filtrates were neutralized with acetic acid $(0.06 \mathrm{~mL})$ and concentrated to dryness. The residue was desalted with Sephadex G-10 eluted with $20 \mathrm{mM}$ triethylammonium acetate $\mathrm{pH}$ 7.5. The fractions containing the oligonucleotide were combined and concentrated to dryness. The residue was treated with $2 \mathrm{~mL}$ of a concentrated ammonia solution at $55^{\circ} \mathrm{C}$ for $16 \mathrm{~h}$ and proceeded as described for the standard deprotection.

Oligonucleotides with the DMT group at the 5'-end were purified using COP $^{\mathrm{TM}}$ cartridges (Cruachem Ltd, Scotland) following the instructions of the manufacturers. Further purification was achieved by reversed phase HPLC. HPLC conditions were as follows: Column: Nucleosil $120 \mathrm{C}_{18}(200 \times 4 \mathrm{~mm})$, flow rate $1 \mathrm{~mL} / \mathrm{min}$, a $20 \mathrm{~min}$ linear gradient from 2 to $25 \%$ acetonitrile over $20 \mathrm{mM}$ aq triethylammonium acetate. In all cases a major peak was observed except in the synthesis of 5'CACCGACGGCGC-phosphate- $\left(\mathrm{CH}_{2}\right)_{6}$ $\mathrm{NH}_{2}$ prepared using the FMOC solid support in where some other products were observed. Characterization by mass spectrometry and yields are shown in Table 1.

\section{Melting studies}

Solutions of equimolar amounts of oligonucleotide A (5'CACCGACGGCGC3') and the appropriate complementary sequence (3'GTGGCTGCCGCG5', 3'GTGGCTGCCGCGG 5' and 3'GTGGCTGCCGCGA5') were mixed in $0.15 \mathrm{M}$ $\mathrm{NaCl} 0.05 \mathrm{M}$ Tris-HC1 $\mathrm{pH} 7.5$ buffer. The solutions were heated at $80^{\circ} \mathrm{C}$ and allowed to cool slowly to room temperature and samples were kept in the refrigerator overnight. UV absorption spectra and melting experiments 
(absorbance versus temperature) were recorded in $1 \mathrm{~cm}$ path-length cells using a spectrophotometer, which has a temperature controller with a programmed temperature increase of $0.5^{\circ} \mathrm{min}^{-1}$. Melts were run on duplex concentration of $4 \mu \mathrm{M}$ at $260 \mathrm{~nm}$.

\section{Phosphodiesterase degradation studies}

$0.4 \mathrm{OD}$ units at $260 \mathrm{~nm}(0.013 \mathrm{mg})$ of each 3'-modified dodecamers were dissolved in $1 \mathrm{~mL}$ of a buffer containing $0.1 \mathrm{M}$ Tris- $\mathrm{HC} 1 \mathrm{pH} 8.6,0.1 \mathrm{M} \mathrm{NaCl}$, and $14 \mathrm{mM} \mathrm{MgCl}_{2}$. To the solution $1 \mu \mathrm{L}$ of a commercial solution of snake venom phosphodiesterase (Boehringer Mannheim) was added and the sample was maintained at $37^{\circ} \mathrm{C}$. The increase on the absorbance at 260 $\mathrm{nm}$ was measured every $30 \mathrm{~s}$ for at least $6 \mathrm{~h}$. The absorption versus time curve of the digestion was plotted from which half-life was calculated assuming a first-order kinetic.

\section{Preparation of oligonucleotide-dexamethasone and fluoresceine conjugates.}

Dexamethasone. Three OD units at $260 \mathrm{~nm}$ (approximately $0.1 \mathrm{mg}$ ) of dodecamer R5N6 were dissolved in $0.3 \mathrm{~mL}$ of water. Then $0.2 \mathrm{~mL}$ of $1 \mathrm{M}$ sodium carbonate buffer $\mathrm{pH} 9.0$ were added together with a solution made with $5 \mathrm{mg}$ of dexamethasone hemisuccinamic acid $\mathrm{N}$-hydroxysuccinimide ester (28) and $0.5 \mathrm{~mL}$ of DMF. After $30 \mathrm{~min}$ at room temperature, the solution was concentrated to dryness and the residue was dissolved in water and filtered. The resulting solution was injected into the HPLC. HPLC conditions were the same as described in oligonucleotide purification with the exception of the gradient. In this case a 40 min gradient from 2 to $45 \%$ acetonitrile was used. The retention time of dexamethasone dodecamer was $21.3 \mathrm{~min}$ ( $65 \%$ of the total area). Yield: 1.2 OD units (40\%). MS: $\mathrm{M}+2 \mathrm{Na}$ 4316.0, expected M 4273.

Fluoresceine. Three OD units at $260 \mathrm{~nm}$ (approximately $0.1 \mathrm{mg}$ ) of dodecamer R5N3 were dissolved in $0.3 \mathrm{~mL}$ of $0.5 \mathrm{M}$ sodium carbonate buffer $\mathrm{pH}$ 9.0. To this solution was added $3 \mathrm{mg}$ of fluorescein-4(5)carboxamido caproic acid $\mathrm{N}$-hydroxysuccinimide ester (Fluka) dissolved in $0.3 \mathrm{~mL}$ of DMF. After $6 \mathrm{~h}$ at room temperature, the solution was concentrated to dryness and the residue was purified by Sephadex G-10 and HPLC as described before. The conversion to the fluoresceine product was $70 \%$ as judged by the area of the peaks on the HPLC chromatogram. Yield: $1.40 \mathrm{D}$ (47\%). HPLC (40 min gradient from $2 \%$ to $40 \%$ acetonitrile) retention time $21.5 \mathrm{~min}$. UV $\max$ (water): 255 and $494 \mathrm{~nm}$. MS: M 4224.0, expected M 4224.5.

\section{Mass spectrometry analysis of oligonucleotides}

The MS were acquired on an API III triple quadrupole mass spectrometer cell (Perkin-Elmer Sciex Instruments, Thornhill, Canada) and a NanoElectrospray ion source developed in our group $(24,25)$.

Needles were prepared as previously described (25). They were typically filled with $0.5-1 \mu \mathrm{L}$ of sample solution with analyte concentration of $1-5$ pmoles/ $\mu \mathrm{L}$ in $50 \%$ methanol and $2-5 \%$ ammonia.

\section{Acknowledgments}


Financial support from CICYT (PB92-0043) and E.E.C.C. Biomedicine and Health Programme (BMH1-CT93-1669) is gratefully acknowledged. We thank Drs P. Herdewijn, A. van Aerschot, T. Saison- Behmoaras, and W. Pfleiderer for their helpful suggestions. We are grateful to Marten Wiersma for his technical assistance.

\section{References}

1. Agrawal, S. In Methods in Molecular Biology Vol. 26: Protocols for Oligonucleotide Conjugates; Agrawal, S., Ed.; Humana: Totowa, 1994; pp 93-120.

2. Manoharan, M. Antisense Research and Applications; Crooke, S. T.; Lebleu, B., Eds.; CRC: Boca Raton, 1993; pp 303-349.

3. Gamper, H. B.; Reed, M. W.; Cox, T.; Virosco, J. S.; Adams, A. D.; Gall, A. A.; Schoeller, J. K.; Meyer, R. B. Nucleic Acids Res. 1993, 21, 145.

4. Sinha, N. D.; Striepeke, S. In Oligonucleotides and Analogues. A Practical Approach; Eckstein, F., Ed.; IRL: Oxford, 1991; pp 185-210.

5. Nelson, P. S.; Frye, R. A.; Liu, E. Nucl. Acids Res. 1989, 17, 7187.

6. Nelson, P. S.; Kent, M.; Muthini, S. Nucl. Acids Res. 1992, 20, 6253.

7. Thanden, J.; Miller, P. S. Bioconj. Chem. 1993, 4, 395.

8. Behrens, C.; Petersen, K. H.; Egholm, M.; Nielsen, J.; Buchardt, O.; Dahl, O. Bioorg. Med. Chem. Lett. 1995, 5, 1785.

9. Gryanov, S. M.; Letsinger, R. L. Tetrahedron Lett. 1993, 34, 1261.

10. Gryanov, S. M.; Letsinger, R. L. Nucl. Acids Res. 1992, 20, 3403.

11. Petrie, C. R.; Reed, M. W.; Adams, A. D.; Meyer, R. B. Bioconj. Chem. $1992,3,85$.

12. Hovinen, J.; Guzaev, A.; Azhayez, A.; Lönnberg, H. Tetrahedron 1994, 50, 7203.

13. Usseline, U.; Thuong, N. T. Tetrahedron Lett. 1990, 31, 81.

14. Manoharan, M.; Tivel, K. L.; Cook, D;, T. P. Tetrahedron Lett. 1995, 36, 3651.

15. Eritja, R.; Robles, J.; Aviñó, A.; Albericio, F.; Pedroso, E. Tetrahedron $1992,48,4171$.

16. Rabanal, F.; Giralt, E.; Albericio, F. Tetrahedron Lett. 1992, 24, 1775.

17. Zuckermann, R.; Corey, D.; Schultz, P. Nucl. Acids Res. 1987, 15, 5305.

18. Glinski, R. P.; Khan, M. S.; Kalamas, R. L.; Spron, M. B. J. Org. Chem. $1973,38,4299$.

19. Chen, J.-K.; Schultz, R. G.; Lloyd, D. H.; Gryaznov, S. M. Nucl. Acids ICes. 1995, 23, 2661.

20. Holletz, T.; Cech, D. Synthesis 1994, 789.

21. Duroux, I.; Godard, G.; Boidot-Forget, M.; Schwab, G.; Hélène, C.; Saison-Behmoaras, T. Nucl. Acids Res. 1995, 23, 3411.

22. Eritja, R.; Walker, P. A.; Randall, S. K.; Goodman, M. F.; Kaplan, B. E. Nucleosides Nucleotides 1987, 6, 803.

23. Mann, M.; Wilm, M. Trends Biochem. Ins. 1995, 20, 219.

24. Wilm, M. S.; Mann, M. Int. J. Mass Spectrom. Ion Processes 1994, 136, 167.

25. Wilm, M.; Mann, M. Analyt. Chem. 1996, 68, 1.

26. Morgan, R. L.; Celebuski, J. E.; Fino, J. R. Nucl. Acids Res. 1993, 21, 4574.

27. Zendegui, J. G.; Vasquez, K. M.; Tinsley, J. H.; Kessler, D. J.; Hogan, M. E. Nucl. Acids Res. 1992, 20, 307. 
28. Acedo, M.; Tarrason, G.; Piulats, J.; Mann, M.; Wilm, M.; Eritja, R. Bioorg. Med. Chem. Lett. 1995, 5, 1577. 